\title{
Mathematics Belief and The Use of Metacognitive Strategy in Arithmetics Word Problem Completion Among 3rd Grade Elementary School Students
}

\author{
Josephine Indah Setyawati ${ }^{1}$, Stephanie Yuanita Indrasari ${ }^{2}$ \\ ${ }^{1,2}$ Faculty of Psychology, University of Indonesia, Depok, Indonesia \\ *E-mail: stephanie.yuanita@ui.ac.id
}

\begin{abstract}
This research aimed to see the relationship between mathematics belief and the use of metacognitive strategy in 3rd-grade elementary students tasked with completing arithmetics word problem. Based on a phenomenon that Indonesian students' performance is still lower than the other countries, this study was also based on the theory that metacognitive strategy and mathematics belief had an impact on arithmetics word problem completion. Ninety-six 3rdgrade elementary school students in Depok, West Java, participated in this study. Knowledge Monitoring Assessment (KMA) was used as an instrument to measure mathematics belief and the Think-Aloud technique was used to measure metacognitive strategy. Pearson-correlation statistical analysis was used to see a relationship between mathematics belief and metacognitive strategy. The result showed that there was a positive and significant relationship between mathematics belief and metacognitive strategy $(r=0,30, p>0,01$, one-tailed). This meant that students who had a better belief in their competence in mathematics would more likely use better metacognitive strategy.
\end{abstract}

Keywords: mathematics belief; metacognitive strategy

\section{Introduction}

Mathematics is a compulsory subject in every level of education degree in Indonesia. Mathematics has already being taught to students since kindergarten to college level. The concept of mathematics is taught from the simplest to the most difficult. Even though it has been learned since elementary school, mathematics still being considered as a difficult subject. The perception of difficulties in studying mathematics makes Indonesian student's achievements lower than other countries. The evidence showed by Trens International Mathematics and Science Studies (TIMMS) assessment, an international survey of mathematics and science learning comparison between several countries, held every four years since 1995 by International Association for the Evaluation of Educational Achievement (IEA). This survey specialized for 4th-grade and 8th-grade students. In 2015, 4th-grade Indonesian students are placed in 44 positions from 49 countries (Mullis, Martin, Foy, \& Hooper, 2016).
The 3rd-grade of elementary school is already given more complex mathematics problems. Of course, this condition will trigger a metacognitive process in these students because it has started many given a difficult problem. In the middle childhood development, students are already at the stage of cognitive development of concrete operational according to Piaget (Papalia \& Martorell, 2014). With regard to mathematics, children who are at this stage are able to begin learning to solve the word problem (Papalia \& Martorell, 2014). The word problems itself is a problem of mathematics given in the form of language (Fuchs, et al., 2006). In early childhood, students begin to develop self-efficacy beliefs in the academic field of school, that is, children begin to develop their self-confidence to master things in school and are confident that they can manage their own learning (Papalia \& Martorell, 2014). This can affect the level of confidence in the mathematical tasks that must be done.

In mathematics learning process, students need to involve their cognitive function, which is not only 
cognitive skill but also the metacognitive skill. Cognitive skill is needed when facing a simple problem, and metacognitive skill is used for a complete complex problem. (Tanner \& Jones, in Desoete, 2009a). Furthermore, in the mathematics thinking process, there are things that also have an impact, that our knowledge base, problem-solving strategies, control and monitoring, belief and effect, and practices (Schoenfeld, 1992).

Metacognition is defined as a process of thinking about cognitive processes (Flavell, 1979). Metacognition has three components, including metacognitive knowledge, metacognitive experience, and metacognitive skills. Metacognitive knowledge is defined as the interaction of variables that influence cognitive outcomes (Flavell, 1979). The metacognitive experience is defined by Flavell (in Ozsoy, 2011) as the awareness and feelings that arise in the individual while working on a task and processing information related to the task. Metacognitive skills are defined as the ability of individuals to use strategies with the aim of controlling their cognition (Efklides, 2008; Flavell in Schneider \& Artlet, 2010). Metacognition strategies themselves fall into one of the variables of metacognitive knowledge, and the use of these strategies requires metacognitive skills.

In the process of mathematics' problem solving, metacognitive skills are required and can be implemented in the solution process. Metacognitive skills include prediction, planning, monitoring, and evaluation (Lucangeli \& Carnoldi, in Desoete et al., 2001). Desoete et al. (2001) explain that predictions are made in working on mathematical problems when individuals can differentiate problems based on their difficulties, so as to focus more on issues that require more effort. Planning includes individual activities to devise strategies for working on problems. Monitoring is related to monitoring whether it has been running the plan, and finally, the evaluation to judge for themselves whether the learning process has been effective or not. Further, Desoete (in Jacobse \& Harskamp, 2012) says that while learning mathematics, metacognitive monitoring is used to identify a problem and modify behavior when needed.

Next is the mathematics belief. Belief is defined as a proposition about math, conscious or unconscious, based on what was done at said, usually starting with the words "I am confident that ...." (Rokeach in Breiteig, et al., 2005). This belief is said by Beriteig, et al. (2005) as one part of the cognitive component that shapes attitude or attitude. In this study, the definition of mathematical beliefs using the theory of Schraw (2009), i.e. individual assessment done regarding how confident he can do the work of the learning process and performance when faced with the task. The mathematics belief influences the process of learning mathematics to students in school, especially in the problem-solving process. Student's belief in mathematics shapes students' behavior in learning math but sometimes has negative consequences (NAEP, in Schoenfeld, 1992). A study of mathematics beliefs, examining student beliefs about how long it takes to solve a problem, produces a phenomenon. The phenomenon that is on the students who have high mathematics confidence, when a failure in the process of problem-solving, will give up more quickly (Schoenfeld, 1992).

This study would examine further the relationship between mathematics belief with metacognitive skill, or more specifically on the use of metacognitive strategies of these students. This study was based on the question whether there was a relationship between mathematics beliefs and the use of metacognitive strategies in solving the arithmetics word problem in 3rd-grade elementary school students. This research was conducted in accordance with the purpose of testing whether students' beliefs had a relationship with the use of metacognition strategies students when solving math problems that were considered difficult in 3rd grade.

\section{Methods}

Sample. This study consisted of 96 samples of participants. Characteristics of these samples were students with male and female gender, age between 8-10 years, 3rd grades in Depok's elementary schools, and had the minimum average level of intelligence based on Coloured Progressive Matrices (CPM) intelligence measurement. For the school characteristic, the researcher chose one private school and one public school in Depok. This research used accidental sampling method, preceded by screening process using CPM.

Research Design. This research was correlational research type, aimed to see if there was a correlation between mathematics belief and metacognitive strategy use in arithmetics word problem completion among 3rd-grade elementary school students. The design of this research was classified as cross-sectional, retrospective, and nonexperimental research (Kumar, 2011). 
Instrument and Measurement. This research used Coloured Progressive Matrices (CPM), Knowledge Monitoring Assessment (KMA), and Think Aloud technique.

CPM was one of the Raven Progressive Matrices (RPM) series, an instrument to measure intelligence. Specifically, CPM was used to measure children's intelligence level. CPM had a colorful background, so it made children interested to work with the items (Raven \& Raven, 2003). CPM consisted of three sets and had twelve items each set. CPM was scored by corrected answers counts from each set, and the total score would be classified to intelligence level in accordance with the age. The result of this total score determined which sample could be a participant in this research. Participants for this research must be in the level III (average), II (above average), and I (superior) of the intelligence.

Knowledge Monitoring Assessment (KMA). KMA was an instrument to measure mathematics belief. This instrument had 15 arithmetics problems, with alpha coefficient 0,656 . KMA consists of two parts. For the first part, the participant needed to read 15 arithmetics problems and chose if they were sure or were not sure that they could solve each item. For the second part, participants were given the same item, but they had to do the test. This research used Hamann coefficient to compute the score. By using Hamann coefficient, the score of discrepancy would be count between the hit and misses answers based on their belief.

Think-Aloud. This technique was used to measure metacognitive strategies. With this technique, participants were given two arithmetics word problem protocols which difficulty level are higher than general problems. In solving problems with this technique, participants had to solve the problems and told their way when solving the problems verbally. When using this technique, it should be recorded and transcripted. Toward the transcript, it given metacognitive strategy codes based on the definition of each strategy. For every metacognitive strategy which emerged, it was given one score. And the total score for this instrument was being correlated with the total score from KMA.

Procedure. This research started with instruments preparation, which was KMA to measure mathematics belief and think-aloud to measure metacognitive strategy. For KMA, researchers initially made 26 math problems consisting of 13 regular computational problems and 13 stories. To make this math problem, researchers collaborated with other researchers who examined mathematical achievement, since this math problem would also be used to examine mathematical achievement. After combined, 54 mathematics questions would be eliminated based on expert judgment, namely primary school teachers to determine whether the compiled questions would be able to be done by the students and also determined the difficulty of each questions.

For KMA measurements, researchers created a form that contained math problems that have been prepared, given the choice sure and not sure in addition to each question. The choice was sure to be selected by the participant if the participant was confident that they could work on the problem and the option was not sure if the participant was unsure of the problem. For metacognitive measurement, two mathematics problems were created that had a higher difficulty level than the difficulty level of a normal 3rd-grade. Then each measuring tool was given to the expert to do expert judgment.

After preparing the measuring instrument, a licensing procedure was conducted to the target school of the research sample. The research team took care of the permit and contacted the target school. At the targeted school, it was explained about the data retrieval procedure, including the IQ test process. The research team also drafted the informed consent to be given to the parents of the students from the intended school containing the consent of the parent or guardian of the child that the child was a research participant.

The next stage was the trial of the participant sample was different from the target participants, with the same sample characteristics as the target participants. This stage was done to test whether the problems given can be done by the participants and whether the problems that exist could indeed trigger the emergence of metacognitive strategies and beliefs. The trial session was also done to find out how much time required for participants to work on the problem.

In the implementation stage, screening of students was first performed to determine the participants according to the criteria of students in 3rd-grade students who had an IQ level above the average. For the screening process of the participants, researchers 
used the intelligence test instrument CPM which was intended for children. Researchers who did not yet have the capacity to administer the test asked two Education psychologists for help. In the test administration process, students were divided into several waves, where one wave consisted of only 10 children. Taking turns, each wave performed the CPM test individually, with a maximum time limit of 25 minutes per child. However, in the process, students were able to complete the test not until the maximum deadline has been determined. Then the CPM test results were scored by calculating the correct answer for each section. The total score of the three parts of the CPM test had further classified the level of intelligence, according to his age. Students who entered the criteria were students whose level of intelligence was in groups III to I, which meant being in the average to superior groups.

In the process of giving KMA tests, first, a number of mathematical questions were asked which students were asked to assess how confident they were to work on the problem. Then the students did the question and counted the number of questions that results in accordance with the beliefs of students before doing it.

Furthermore, the results were processed to get the score by using several ways. During working on the problem, students also had to do math problems with Think-aloud techniques while recorded, to know metacognitive strategies used by students.

After working on the problem, then the data is processed by verbatim from the recordings for metacognition measurement. Then calculate the KMA score by using one of several calculation ways. Finally, statistical analysis using Pearsoncorrelation was performed by correlating the scores of the KMA tests with the results of the tests using the Think-Aloud technique.

\section{Results}

Based on research results, it was known that the amount of data that could be processed amounted to 96 data from 96 participants. Of the 96 participants who were the subjects of the study, 49 participants or $51 \%$ of participants were female, and as many as 47 participants or $49 \%$ of participants were male. This showed that the proportion of gender of participants was quite balanced. Based on the origin of the school, participants from private elementary schools were as much as $57.3 \%$ and participants coming from public elementary school were as much as $42.7 \%$. From this, it could be concluded that the data could be processed more from private elementary schools.

Based on the age aspect, participants were divided from 8 years of age, 8.5 years, 9 years, 9.5 years, and 10 years. the most participants are at the age of 9 years with $47.9 \%$, followed by 9.5 years old with the percentage of $21.9 \%, 8.5$ years with $15.6 \%, 8$ years age of $9.4 \%$, and participants who were at the age of 10 years at the least with a percentage of $5.2 \%$. From the data, it could be concluded that the age comparison of participants was not balanced.

Based on the level of intelligence, there were $55.2 \%$ participants who were in the group I or superior based on CPM score. Participants who were in Group II or above average as much as $31.3 \%$, and participants who were in Group III or group average as much as $13.5 \%$. From these results, it was known that the study participants were still dominated by students with a superior level of intelligence.

The main result of this study was the result of Pearson-correlation statistical analysis between mathematics belief and the use of metacognitive strategy. Based on the results, it was known that there was a positive and significant relationship between mathematics belief and metacognitive strategy $(\mathrm{r}=0.300, \mathrm{n}=96, \mathrm{p}<.01$, one-tail $)$. This indicated that the higher the students' confidence in their mathematical ability, the more metacognitive strategies used by the students. From that result, it could be seen that $\mathrm{r} 2=0.09$, meaning that only $9 \%$ variance of mathematics beliefs could be explained by metacognitive strategy, while $91 \%$ of other variance was explained by other factors not mentioned or described in this study. This $\mathrm{r} 2$ value also showed the correlation strength between variables. In this study, the $\mathrm{r}$ value was 0.3 , meaning that there was the correlation with moderate relationship (Gravetter \& Wallnau, 2013).

Based on the results of research, it could also know what strategy was the most widely used by participants. Once analyzed, hypothesizing was the most used by participants. The description of the number of each metacognitive strategy's users could be seen from the following graph: 
Table 1.

Descriptive statistic of metacognitive strategy on mathematics

\begin{tabular}{cc}
\hline Strategy & Amount of User \\
\hline Hypothesizing & 96 \\
Estimating & 65 \\
Checking 1 & 12 \\
Checking 2 & 10 \\
Attention Control & 65 \\
Self-correction & 42 \\
Evaluation & 19 \\
Confirming & 56 \\
Self-evaluation & 29 \\
\hline
\end{tabular}

Based on the research results, it could also be seen that there were differences in the mean score of significant mathematical beliefs between classes of IQ on average, above average, and superior. However, in this study, there was no difference in mean scores on the use of metacognition strategies that were significant between IQ groups.

\section{Discussion \& Conclusion}

Discussion. The result shows that there was a positive and significant correlation between mathematics belief and metacognitive strategy used in arithmetics word problems among 3rd-grade elementary school students. This result confirmed the theory which stated that arithmetics problem solving was affected by student's belief as a problem solver (Schoenfeld, 1992) and metacognitive skill to resolve complex problems (Tanner \& Jones, in Desoete, 2009a).

The result also showed that 3rd-grade students in Depok area were able to use their metacognitive strategies. This was in accordance to statement from Kreutzer, Leonard, and Flavell (in Schneider \& Artelt, 2010) that when a child was already 8 or 9 years old, they started to complete their metacognitive skills.

This research also found metacognitive strategies that were used by participants, which were hypothesizing, estimating, checking, attention control, self-correction, evaluation, confirming and self-evaluation. These strategies were included in the metacognitive skill which was consisted of four steps, which were planning, predicting, monitoring, and evaluation (Lucangeli \& Carnoldi, in Desoete et al., 2001). According to Montague and Applegate (1993), the emerging of metacognitive strategies provides evidence that in the arithmetics problemsolving, it was affected by metacognitive strategies.
In this research, according to Fuchs, et al. (2006), arithmetics word problems completion also needed cognitive abilities, that were working memory, long-term memory, attentive behavior, nonverbal problem solving, linguistic skill, reading skill, and concept comprehension. According to those theories, the result also provided the evidence. To complete the word problems, participants had to do information selection to know which was the relevant information to be the clue to resolve problems. Information selection needed attentive behavior skill, it meant that participants have to choose the relevant information (Fuchs, et al., 2006).

Based on the researcher observation, in the beginning of the problem-solving process, participants could start with reading the problem. Some participants looked confused to choose the right strategy to complete the problems because some of them were confused with the statement in the problem. This was shown by some students were asking the researcher what was the meaning of the problem. This was according to Fuchs, et al. (2006), that students needed good linguistic skill and good reading skill to resolve word problems.

On the word problems completion process, participants also did the arithmetics operation according to the problems. In this research, it was found that some participants did not understand the concept of some mathematics operation such as multiplication, division, and still many participants did not understand the meaning of the word "divided equally". This phenomenon was proving that in completing word problems, it needed concept comprehension, where students needed to understand problem's concept so they could choose the right operation to complete the problems efficiently.

In this research, it was also found that there was a minus on mathematics belief score and there was still a low score even though almost every student mostly chooses "sure" option for every item. Nevertheless, their performance's scores were not equal to their belief. This could be explained that 3rd-grade students were in the middle childhood stage. These children are still developing their selfconfident and academic skill, but could not measure up their ability yet (Papalia \& Martorell, 2014). Children's belief could be affected by teachers' teaching method at school or parents' teaching method at home. This condition was confirmed in 
the theory that one of the belief development factors was the student's academic experience at school and teachers' teaching method at school (Schoenfeld, 1992).

Associated with teaching teachers at school and parents at home, according to Carr et al., (1989) also became one of the factors that helped the development of metacognition abilities in students. Students who were accustomed to being taught using the right strategy to solve a problem would certainly use their metacognitive strategies better. However, this could not be ascertained in this study because it did not interview teachers related to the teaching of mathematics in the classroom and did not make direct observations during the learning process of mathematics.

Regarding the limitations of this research, there were some limitations of school sample. The researcher did not choose the schools which have the same standard. In Indonesia, the standard of the school could be known as national accreditation by the ministry of education. The national accreditation could be the measurement of school quality. This could affect the teaching method which also affected the metacognitive strategies used by students.

Based on the findings and the main result of this research, hopefully, it could be an input for teachers at school. By knowing the effectiveness of metacognitive strategies in mathematics learning, teachers could develop their method of teaching, so student also could develop their the metacognitive ability. After students knew how to use their metacognitive strategies in mathematics, they also could use it in other subjects at school.

Conclusions. From this research, it could be concluded that there was a relationship between mathematics belief and metacognitive strategy used in arithmetics problem completion among 3rd-grade elementary school students. It meant students whose better belief toward their mathematics skill will use better metacognitive strategy, vice versa.

\section{References}

Breiteig, T., Grevholm, B., \& Kislenko, K. (2005). Beliefs and attitudes in mathematics teaching and learning. In Nordisk Conference Mathematics Didactic ved NTNU: 15/11/2004-16/11/2004 (pp. 129-138). Department of Geography, Norwegian University of Science and Technology.
Carr, M., Kurtz, B.E., Schneider, W., Turner, L.A., \& Borkowski, J.G., (1989). Strategy acquisition and transfer among American and German children: Environmental influences on metacognitive development. Developmental Psychology, 25 (5), $765-771$.

Desoete, A., Roeyers, H., \& Buysse, A.(2001). Metacognition and mathematical problem-solving in grade 3. Journal of Learning Disabilities, $435-$ 448.

Desoete, A. (2009a). The enigma of mathematical learning disabilities. Dalam D.J.Hacker, J.Dunlosky, \& A.C. Graesser, (Ed.).Handbook of Metacognition in Education (pp. 206 - 218). Madison: Routledge.

Efklides, A. (2008). Metacognition: Defining its facets and levels of functioning in relation to selfregulation and co-regulation. European Psychologist, 13(4), 277-287.

Flavell, J. H. (1979). Metacognition and cognitive monitoring: A new area of cognitivedevelopmental inquiry. American Psychologist, 34(10), 906.

Fuchs, L.S., Fuchs., D., Compton, D.L., Powell, S.R., Seethaler, P.M., Capizzi, A.M., Schatscheider, C., \& Fletcher, J.M. (2006). The cognitive correlates of third-grade skill in arithmetics, algorithmic, computation, and arithmetic word problems. Journal of Education Psychology, 98 (1), 29-43.

Gravetter, F.J., \& Wallnau, L.B. (2013). Statistics for the behavioral sciences, 9th(ed). USA: Wadsworth.

Jacobse, A. E. \& Harskamp, E.G. (2012). Towards efficient measurement of metacognition in mathematical problem-solving. Metacognition Learning, 7, $133-149$.

Kumar, R. (2011). Research methodology 3rd(ed). London: SAGE Publications Ltd.

Montague, M. \& Applegate, B. (1993). Middle school students' mathematical problem-solving: An analysis of Think-Aloud protocols. Learning Disability Quarterly, 16, 19-32.

Mullis, I. V. S., Martin, M. O., Foy, P., \& Hooper, M. (2016). TIMSS 2015 International Results in Mathematics. Retrieved from Boston College, TIMSS \& PIRLS International Study Center website:

http://timssandpirls.bc.edu/timss2015/international -results/.

Papalia, D.E. \& Martorell, G., 2014. Experience human development, 13th Ed. New York, McGraw-Hill.

Raven, J. \& Raven, J. (2003). Raven progressive matrices. In R. S. McCallum (Eds.), Handbook of nonverbal assessment (p. 223 - 237). New York: Plenum Publisher. 
Schneider, W. \& Artelt, C. (2010). Metacognition and mathematics education. ZDM Mathematics Education, 42, 149 - 161.

Schoenfeld, A.H. (1992). Learning to think mathematically: Problem-solving, metacognition, and sense-making in mathematics. Dalam D. Grouws.(Ed). Handbook for Research on Mathematics Teaching and Learning (p. $334-$ 370). New York: Macmillan.
Schraw, G. (2009). Measuring metacognitive judgments. Dalam D.J.Hacker, J.Dunlosky, \& A.C. Graesser, (Ed.). Handbook of Metacognition in Education (p. 415 - 429). Madison: Routledge.

Ozsoy, G. (2011). An investigation of the relationship between metacognition and mathematics achievement. Asia Pacific Education, 12, 227 235. 